Supplement of Atmos. Chem. Phys. Discuss., 14, 13681-13729, 2014

http://www.atmos-chem-phys-discuss.net/acpd-14-13681-2014/

doi:10.5194/acpd-14-13681-2014-supplement

(C) Author(s) 2014. CC Attribution 3.0 License.

(c) (i)

\title{
Impact of the representation of marine stratocumulus clouds on the an- thropogenic aerosol effect
}

D. Neubauer et al.

Correspondence to: D. Neubauer (david.neubauer@env.ethz.ch) 

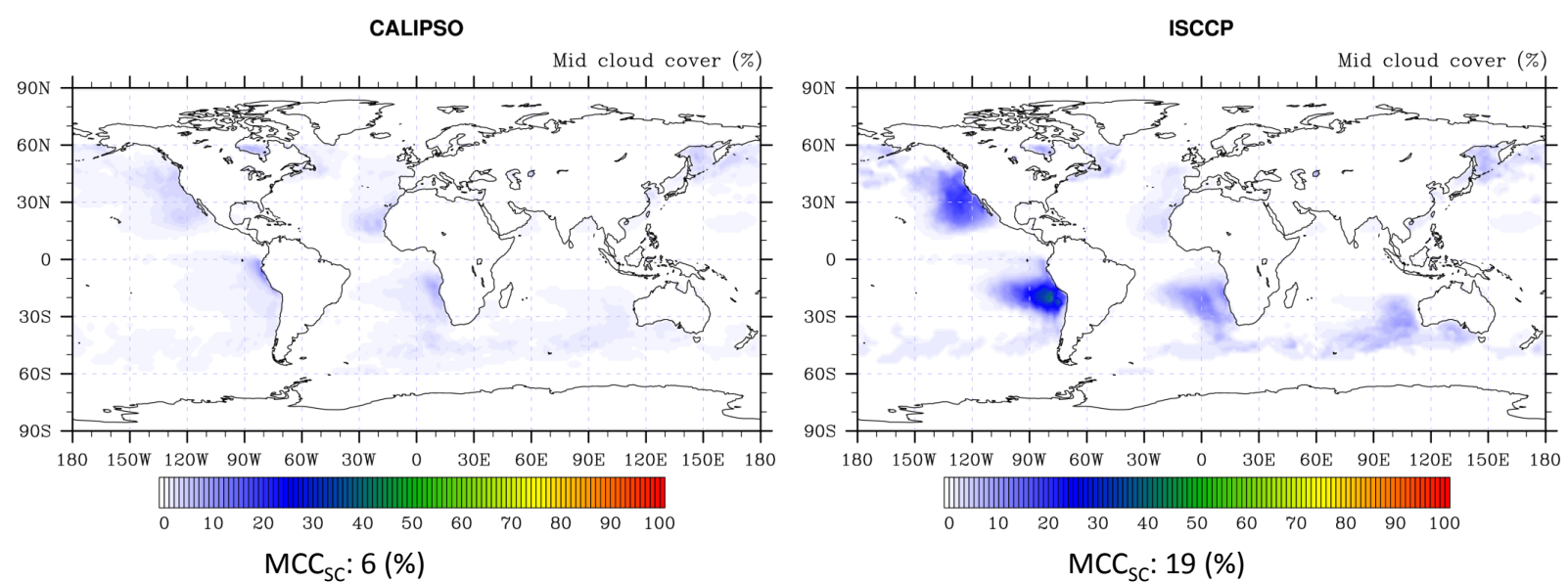
$\mathrm{MCC}_{\mathrm{sc}}: 6(\%)$

ECHAM6-HAM2 (REF)
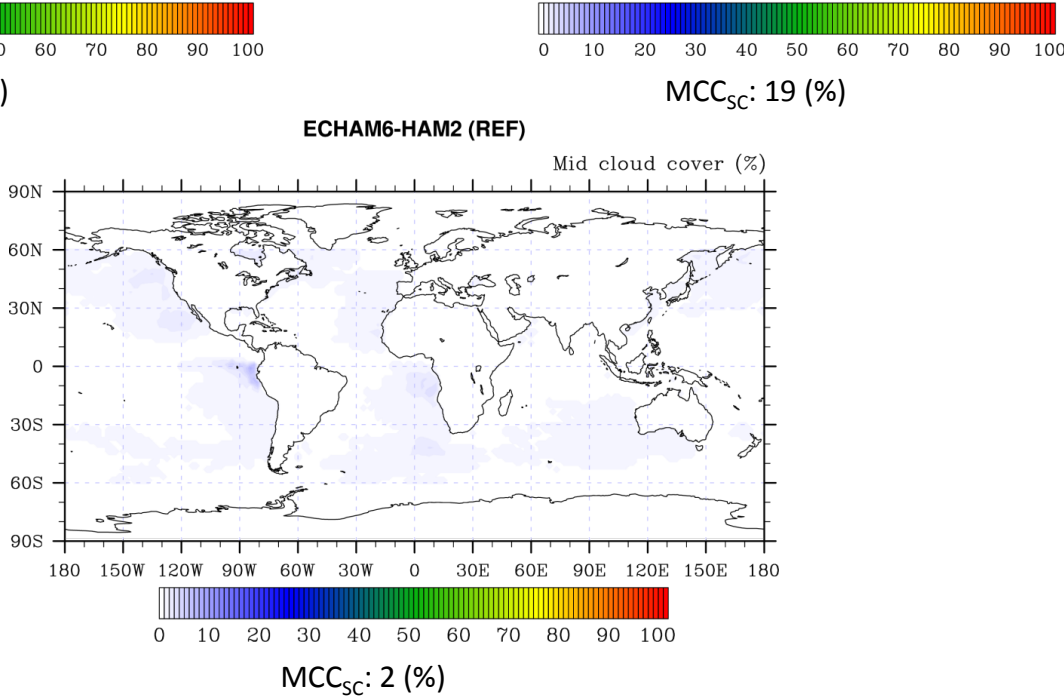

Figure S1. Mid level cloud cover in stratocumulus cloud regions in the reference simulation and the CALIPSO and ISCCP satellite data. Values below each panel show in-regime values (subscript sc). Note that in-regime values are larger than the mean over the stratocumulus cloud regions. 

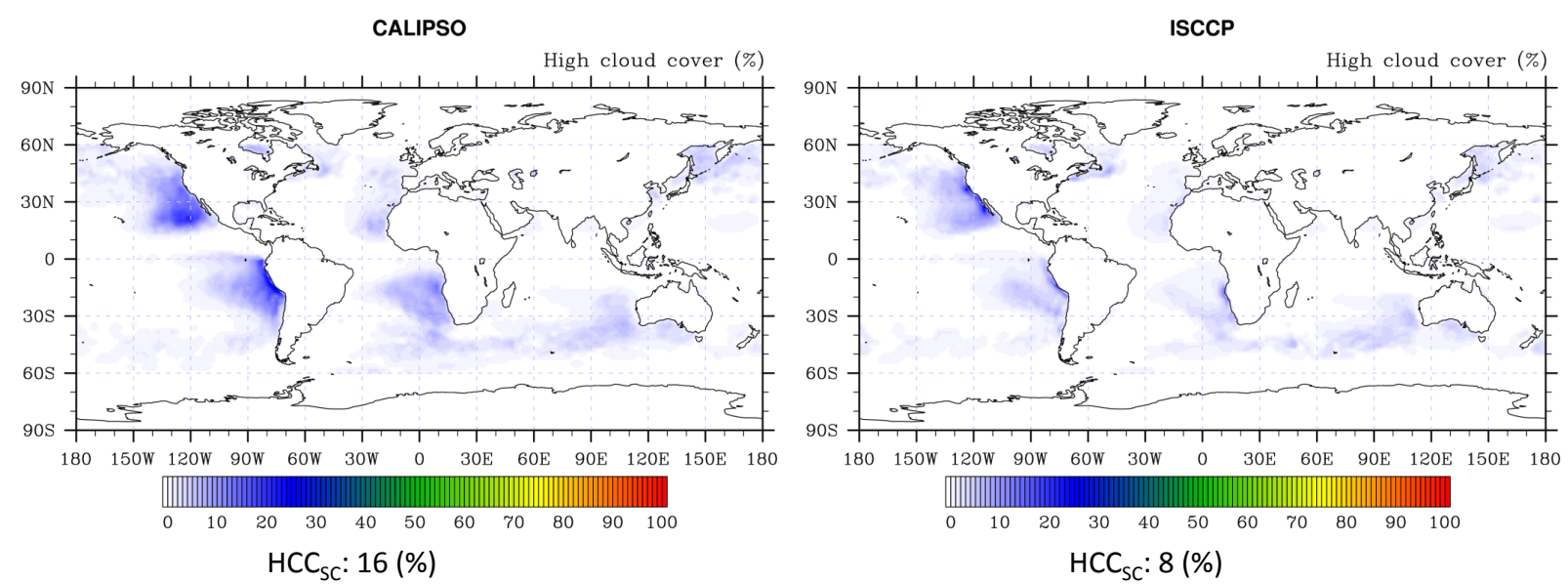
$\mathrm{HCC}_{\mathrm{SC}}: 16(\%)$

ECHAM6-HAM2 (REF)
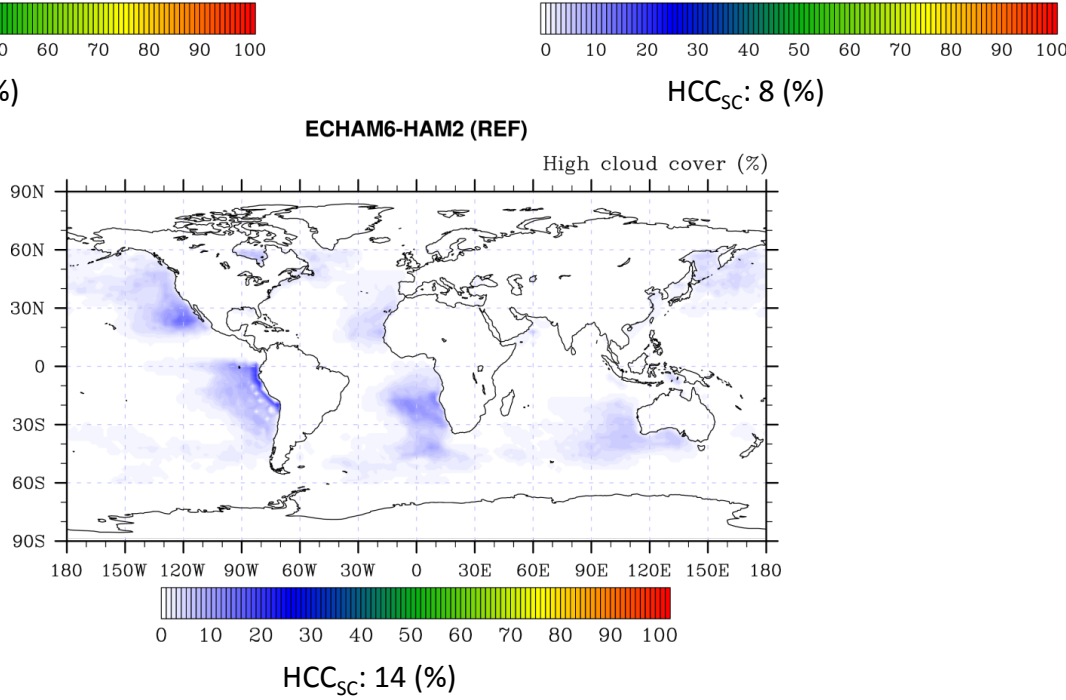

Figure S2. High level cloud cover in stratocumulus cloud regions in the reference simulation and the CALIPSO and ISCCP satellite data. Values below each panel show in-regime values (subscript sc). Note that in-regime values are larger than the mean over the stratocumulus cloud regions. 

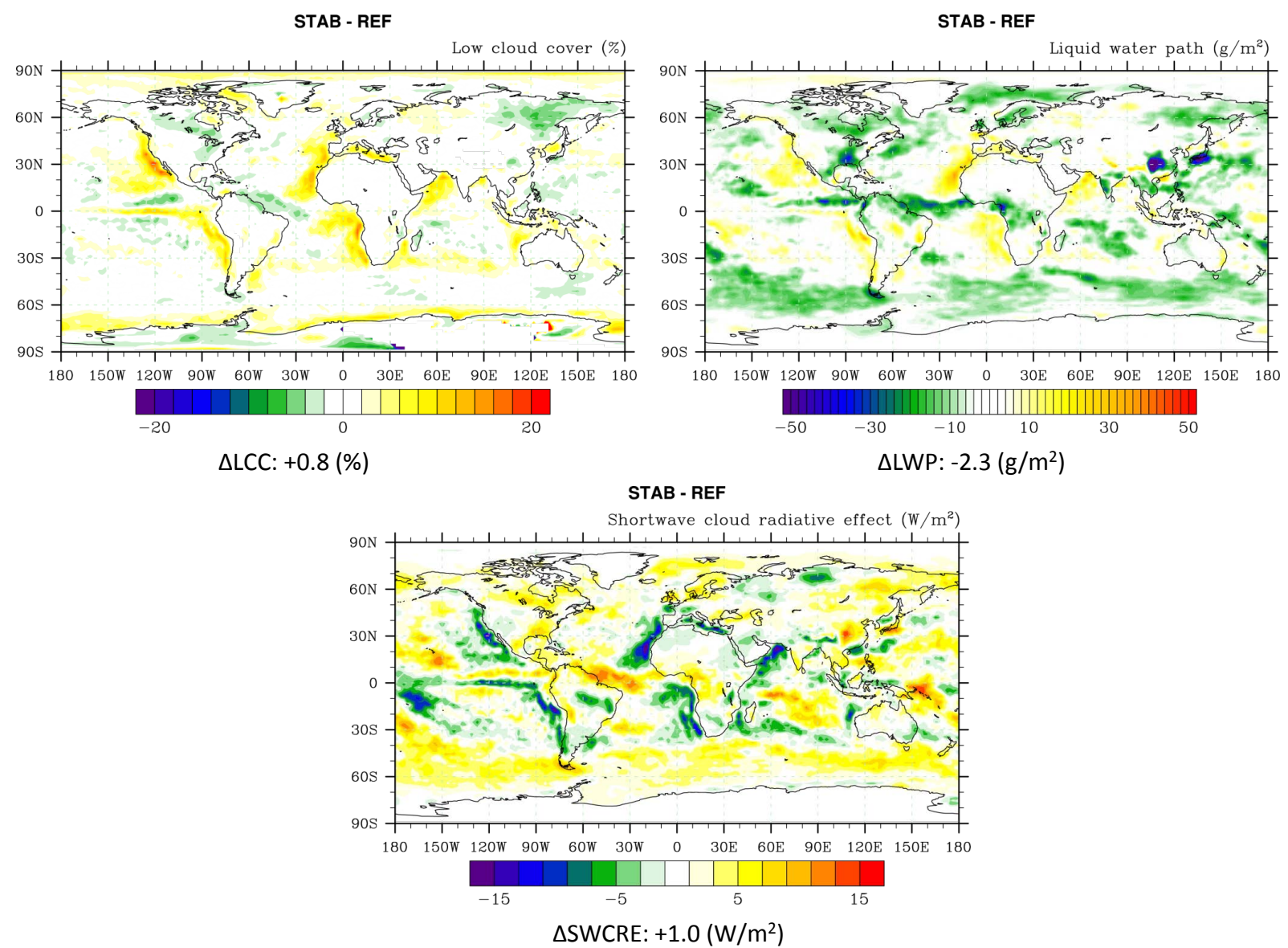

Figure S3. Difference in low cloud cover, LWP and SWCRE globally between a simulation with a 'sharp' stability function and the reference simulation. Values below each panel are global averages. 
ECHAM6-HAM2 (REF)
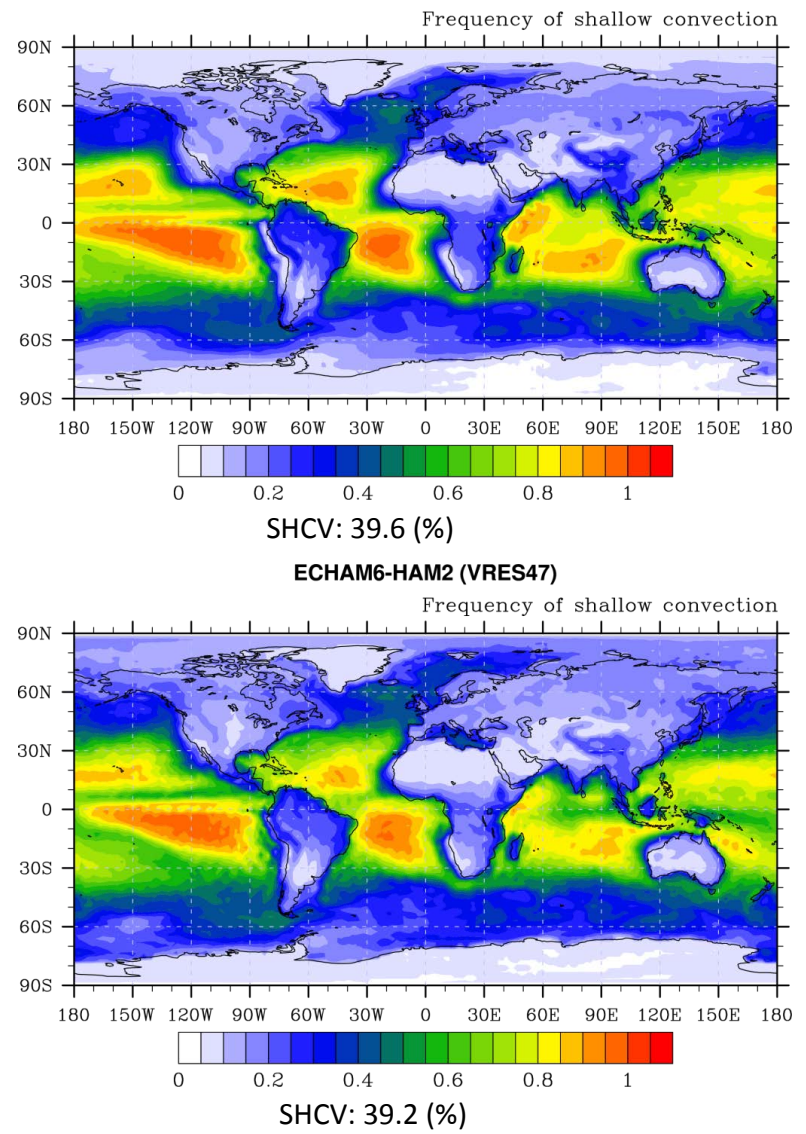

ECHAM6-HAM2 (STAB)

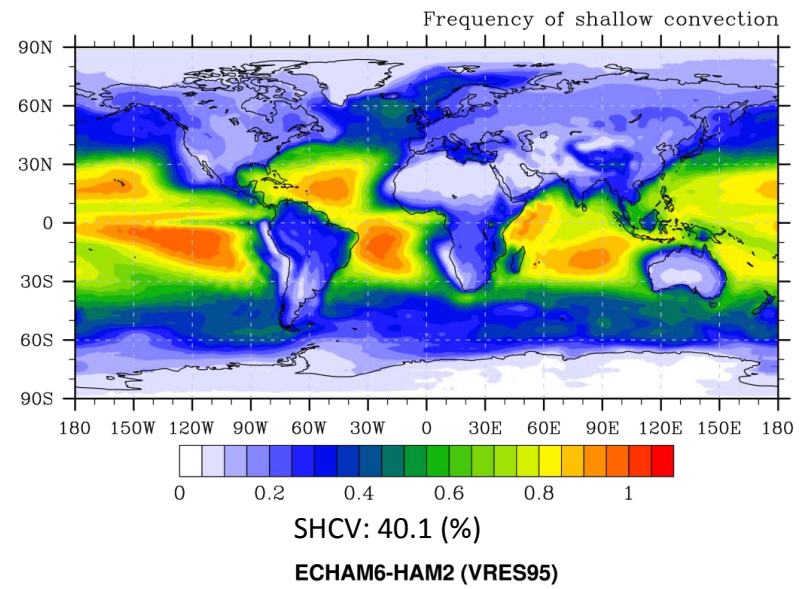

Frequency of shallow convection

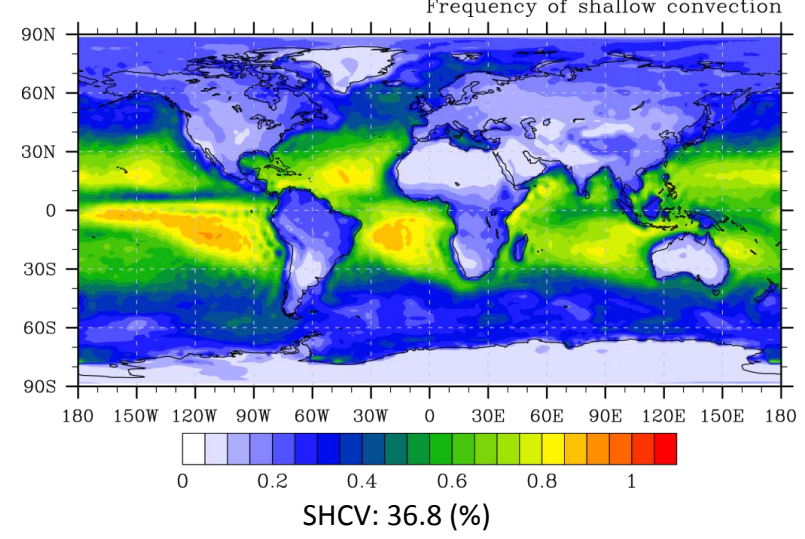

Figure S4. Frequency of the activation of the shallow-convection scheme in the REF, STAB, VRES47 and VRES95 experiments. 
Table S1. Probability that the null hypothesis in an unpaired two tails t-test with unequal variances applied to annual mean values of the present day and pre-industrial aerosol (climatological) simulations of an experiment is rejected. AAE is the anthropogenic aerosol effect, LWP is liquid water path, $\tau$ is aerosol optical depth and $\Delta$ represents the difference between present-day and pre-industrial aerosol emissions. The subscript sc represents values in the stratocumulus regime. Values $<90 \%$ are considered not statistically significant.

\begin{tabular}{lllll}
\hline & Variable & \multicolumn{3}{c}{ Experiment (PD-PIaer) } \\
& REF & STAB & AP & $\begin{array}{l}\text { STAB } \\
+ \text { AP }\end{array}$ \\
\hline AAE $_{\mathrm{Sc}}$ & $91 \%$ & $98 \%$ & $91 \%$ & $69 \%$ \\
$\mathrm{AAE}_{\mathrm{Sc} / \mathrm{SW}}$ & $91 \%$ & $98 \%$ & $88 \%$ & $56 \%$ \\
$\Delta \mathrm{LWP}_{\mathrm{Sc}}$ & $100 \%$ & $100 \%$ & $100 \%$ & $89 \%$ \\
$\Delta \tau_{\mathrm{Sc}}$ & $100 \%$ & $100 \%$ & $100 \%$ & $100 \%$ \\
\hline
\end{tabular}


Table S2. Same as Table S1 but the t-test is applied to annual mean values of (AMIP) simulations of an experiment and the reference experiment. CC stands for cloud cover, SWCRE for shortwave cloud radiative effect, subscript PD for present day aerosol emissions and PIaer for pre-industrial aerosol emissions.

\begin{tabular}{llll}
\hline & Variable & \multicolumn{2}{c}{ Experiment (-REF) } \\
& STAB & AP & $\begin{array}{l}\text { STAB } \\
+ \text { AP }\end{array}$ \\
\hline CC $_{\text {PD }}$ & $100 \%$ & $27 \%$ & $98 \%$ \\
CC $_{\text {PIaer }}$ & $100 \%$ & $38 \%$ & $100 \%$ \\
LWP $_{\text {PD }}$ & $99 \%$ & $32 \%$ & $100 \%$ \\
LWP $_{\text {PIaer }}$ & $100 \%$ & $92 \%$ & $100 \%$ \\
SWCRE $_{\text {PD }}$ & $90 \%$ & $28 \%$ & $99 \%$ \\
SWCRE $_{\text {PIaer }}$ & $98 \%$ & $16 \%$ & $100 \%$ \\
\hline
\end{tabular}

